\title{
Site-specific PEGylation of proteins containing unnatural amino acids
}

\author{
Alexander Deiters, T. Ashton Cropp, Daniel Summerer, \\ Mridul Mukherji and Peter G. Schultz* \\ Department of Chemistry and the Skaggs Institute for Chemical Biology, The Scripps Research Institute, \\ 10550 North Torrey Pines Road, La Jolla, CA 92037, USA
}

\begin{abstract}
Here, we report a generally applicable PEGylation methodology based on the site-specific incorporation of para-azidophenylalanine into proteins in yeast. The azido group was used in a mild [3+2] cycloaddition reaction with an alkyne derivatized PEG reagent to afford selectively PEGylated protein. This strategy should be useful for the generation of selectively PEGylated proteins for therapeutic applications.
\end{abstract}

Despite the importance of proteins as therapeutic agents, they have a number of disadvantages in comparison to small molecule drugs, including poor oral bioavailability and in many cases short serum halflives. The covalent attachment of oligosaccharides and synthetic polymers such as polyethylene glycol to proteins (PEGylation) can significantly enhance protein half-life by shielding ${ }^{1}$ the polypeptide from proteolytic enzymes and increasing the apparent size of the protein, thus reducing clearance rates. Moreover, PEG conjugates can enhance protein solubility and have beneficial effects on biodistribution. The physical and pharmacological properties of PEGylated proteins are affected by the number and the size of PEG chains attached to the polypeptide, the location of the PEG sites, and the chemistry used for PEGylation. Examples of PEG conjugation ${ }^{2}$ to proteins include reactions of $N$-hydroxysuccinimidyl ester derivatized PEGs with lysine, ${ }^{3}$ 1,4-addition reactions of maleimide and vinylsulfone derivatized PEGs with cysteine, and condensation of hydrazide containing PEGs with aldehydes generated by oxidation of glycoproteins. When more than one reactive site is present in a protein (e.g., multiple amino or thiol groups) or reactive electrophiles are used, nonselective attachment

\footnotetext{
${ }^{*}$ Corresponding author. Tel.: +1 858784 9300; fax: +1 858784 9440; e-mail: schultz@scripps.edu
}

of one or multiple PEG molecules can occur, leading to the generation of a heterogeneous mixture that is difficult to separate. The lack of selectivity and positional control in the attachment of PEG chains can lead to significant losses in biological activity and possibly enhanced immunogenicity of the conjugated protein. Here, we report a novel method that allows for the completely site specific and irreversible attachment of PEG chains to proteins based on unnatural amino acid mutagenesis. ${ }^{4}$

Recently, we showed that a variety of unnatural amino acids, including amino acids with alkenyl, iodo, and keto functional groups, as well as glycosylated, redox active, and photo-crosslinking amino acids, can be genetically incorporated into proteins in prokaryotic and eukaryotic organisms with good efficiencies and high selectivities. ${ }^{5-10}$ In addition, it was shown that amino acids with alkenyl, azido, and keto side chains can be used to efficiently couple sugars, biotin, and fluorescent probes to proteins. ${ }^{11-13}$ Because the copper-mediated Huisgen [3+2] cycloaddition ${ }^{14-16}$ of an azide and an alkyne is orthogonal to all functional groups found in proteins and forms a stable triazole linkage, we investigated this reaction for the selective PEGylation of proteins. Moreover, we previously evolved an E. coli tyrosyl tRNA/tRNA-synthetase pair that selectively incorporates 1 into proteins in yeast in response to the amber nonsense codon, TAG. 


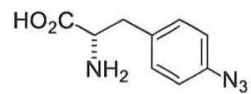

$$
\begin{aligned}
& 1
\end{aligned}
$$

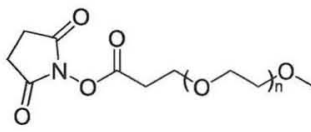

$$
\begin{aligned}
& \text { 2: } 5 \mathrm{kDa} \\
& \text { 3: } 20 \mathrm{kDa}
\end{aligned}
$$

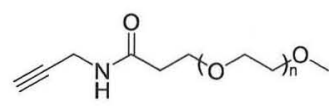

$$
\begin{aligned}
& \text { 4: } 5 \mathrm{kDa} \\
& \text { 5: } 20 \mathrm{kDa}
\end{aligned}
$$

Initially, we chose human superoxide dismutase-1, a key enzyme in preventing the formation of reactive oxygen species in cells, ${ }^{17}$ for PEGylation studies. SOD has been used in the past as a model system to assess chemistries for PEG conjugation. Based on the crystal structure of SOD ${ }^{18}$ the surface exposed residue Trp33 was selected as the PEGylation site (this residue is distal to the active site), and the corresponding codon was mutated to TAG. Expression of 33TAG-SOD, bearing a C-terminal hexahistidine tag, in minimal media supplemented with $1 \mathrm{mM} 1$ afforded mutant protein in a yield of $0.8 \mathrm{mg} / \mathrm{L} .{ }^{6}$ After Ni-NTA chromatography the protein was $>90 \%$ homogeneous as judged by SDS-PAGE and Gelcode Blue staining. Site-specific incorporation of 1 was verified by mass spectrometry. ${ }^{6}$

In order to use a [3+2] cycloaddition reaction for protein pegylation, alkyne bearing PEG reagents $4(5 \mathrm{kDa})$ and $5(20 \mathrm{kDa})$ were synthesized in one step from the corresponding commercially available $N$-hydroxysuccinimide esters 2 and $\mathbf{3}$ (Nektar Therapeutics, San Carlos, CA) by reaction with propargylamine in $\mathrm{CH}_{2} \mathrm{Cl}_{2}$ at room temperature. Site-specific PEGylation was carried out in $0.1 \mathrm{M}$ phosphate buffer $(\mathrm{pH} 8)$ with 33TAG-SOD $(0.5 \mathrm{mg} / \mathrm{mL})$ in the presence of 4 or 5 (40 equiv), $1 \mathrm{mM}$ $\mathrm{CuSO}_{4}, 1 \mathrm{mM}$ tris(1-benzyl-1 $H$-[1,2,3]triazol-4-ylmethyl)amine, and $\sim 1 \mathrm{mg} \mathrm{Cu}$ wire or $2 \mathrm{mM}$ tris(carboxyethyl)phosphine as the reducing agent. After shaking the reaction at $37^{\circ} \mathrm{C}$ overnight, the PEGylated protein was analyzed by SDS-PAGE and a $70-85 \%$ conversion into labeled SOD was detected by densitometry (Fig. 1). Comparison of the protein bands with a standard protein marker revealed apparent sizes of 25 and $48 \mathrm{kDa}$ for the reaction of mutant SOD with 4 and 5 . This apparent higher mass is a typical observation when analyzing PEGylated proteins by SDS-PAGE. ${ }^{20}$ No PEGylation was observed when using wild type SOD as a substrate, demonstrating the high selectivity of this reaction. For comparison wild type SOD was pegylated with commonly used $\mathrm{N}$-hydroxysuccinimide esters 2 and 3 (phosphate buffer, $\mathrm{pH} 7.5,4^{\circ} \mathrm{C}, 1 \mathrm{~h}$ ), leading to a multitude of conjugated proteins as visualized by SDS-PAGE (Fig. 2) (each band is likely composed of a population of positional isomers). ${ }^{19}$

The selective attachment of a single PEG group to the azide containing SOD was verified by MALDI-TOF (a)

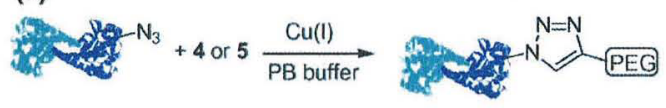

(b)

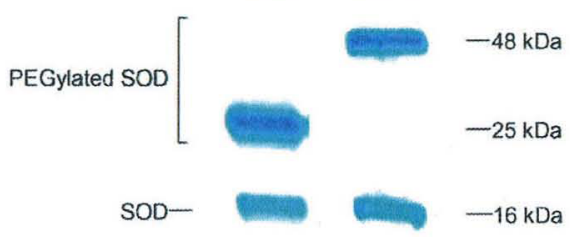

Figure 1. (a) Site-specific PEGylation of 33TAG-SOD by [3+2] cycloaddition. (b) SDS-PAGE gel after Gelcode Blue staining. Lane 1: reaction with $4(5 \mathrm{kDa})$. Lane 2: reaction with $\mathbf{5}(20 \mathrm{kDa})$.

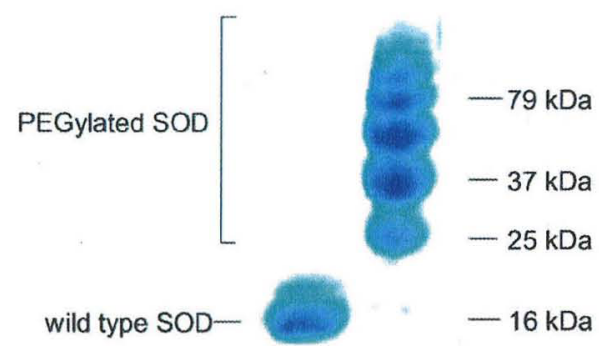

Figure 2. Nonspecific PEGylation of wild type SOD with $2(5 \mathrm{kDa})$.

mass spectrometry of the $5 \mathrm{kDa}$ conjugate (Fig. 3). Although the PEGylation site is defined in the incorporation step, it was verified by disappearance of the peptide VY*GSIK containing the unnatural amino acid 1 (denoted $\mathrm{Y}^{*}$ ) in tryptic mapping of the SOD-4 conjugate. $^{20,21}$ All other fragments expected for trypsinized SOD were detected by liquid chromatography and tandem ion trap mass spectrometry. The enzymatic activities of the two PEGylated derivatives were also assessed and compared to wild type SOD. Measurements were performed using a gel-based assay relying on SOD-induced inhibition of gel staining by superoxide and the dye nitro tetrazolium blue. ${ }^{22}$ The studies revealed no significant loss in activity for the modified SOD derivatives relative to wild type SOD, indicating (a)

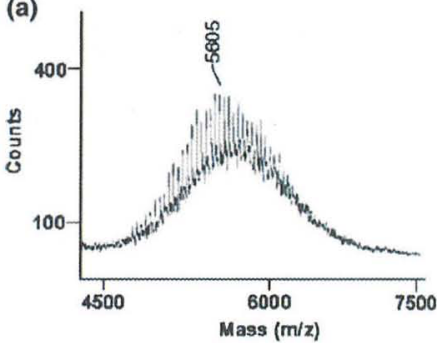

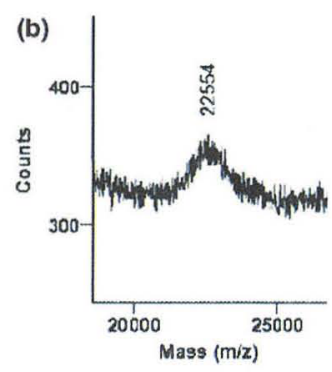

(b)
Figure 3. MALDI-TOF spectrum of 4 (a) and of the SOD-4 conjugate (b). 
that both the reaction conditions and the introduced chemical modifications are accommodated without interfering with proper SOD function. ${ }^{21}$

In summary, we have developed a novel PEGylation technology, which allows the site specific and irreversible attachment of a single PEG molecule to a protein. This makes possible the formation of defined, homogeneous PEGylated proteins for therapeutic applications. Currently, we are exploring alternative chemistries for PEGylation (e.g., addition reactions with keto, thioester, and 1,2-amino alcohol containing amino acids) and the application of this technology to the production of other modified proteins, including PEG-linked homoand heterodimeric proteins.

\section{Acknowledgements}

A.D. gratefully acknowledges a postdoctoral fellowship from the Deutsche Forschungsgemeinschaft. T.A.C. is supported by a National Research Service Award form the National Institutes of Health. This work was supported by funding from the National Institutes of Health (GM62159). We thank the Sharpless group for providing us with the tris(triazolyl)amine ligand. This is manuscript CH-16749 of The Scripps Research Institute.

\section{References and notes}

1. Veronese, F. M.; Harris, J. M. Adv. Drug Deliv. Rev. 2002, 54,453 , and references cited therein.
2. Roberts, M. J.; Bentley, M. D.; Harries, J. M. Adv. Drug Deliv. Rev. 2002, 54, 459.

3. Kinstler, O.; Molineux, G.; Treuheit, L. D.; Gegg, C. Adv. Drug Deliv. Rev. 2002, 54, 477.

4. Wang, L.; Schultz, P. G. Chem. Commun. 2002, $1,1$.

5. Wang, L.; Brock, A.; Herberich, B.; Schultz, P. G. Science 2001, 292, 498.

6. Chin, J. W.; Santoro, S. W.; Martin, A. B.; King, D. S.; Wang, L.; Schultz, P. G. J. Am. Chem. Soc. 2002, 124, 9026.

7. Chin, J. W.; Martin, A. B.; King, D. S.; Wang, L.; Schultz, P. G. Proc. Natl. Acad. Sci. U.S.A. 2002, 99, 11020.

8. Zhang, Z.; Smith, B. A.; Wang, L.; Brock, A.; Cho, C.; Schultz, P. G. Biochemistry 2003, 42, 6735.

9. Chin, J. W.; Cropp, T. A.; Anderson, J. C.; Mukherji, M.; Zhang, Z.; Schultz, P. G. Science 2003, 301, 964.

10. Alfonta, L.; Zhang, Z.; Uryu, S.; Anderson, J. C.; Loo, J. A.; Schultz, P. G. J. Am. Chem. Soc. 2003, 125, 14662.

11. Liu, H.; Wang, L.; Brock, A.; Wong, C.-H.; Schultz, P. G. J. Am. Chem. Soc. 2002, 125, 1702.

12. Wang, L.; Zhang, Z.; Brock, A.; Schultz, P. G. Proc. Natl. Acad. Sci. U.S.A. 2003, 100, 56.

13. Deiters, A.; Cropp, T. A.; Mukherji, M.; Chin, J. W.; Anderson, J. C.; Schultz, P. G. J. Am. Chem. Soc. 2003, $125,11782$.

14. Tornoe, C. W.; Christensen, C.; Meldal, M. J. Org. Chem. 2002, 67, 3057.

15. Rostovtsev, V. V.; Green, L. G.; Fokin, V. V.; Sharpless, K. B. Angew. Chem., Int. Ed. 2002, 41, 596.

16. Wang, Q.; Chan, T. R.; Hilgraf, R.; Fokin, V. V.; Sharpless, K. B.; Finn, M. G. J. Am. Chem. Soc. 2003, $125,3192$.

17. Veronese, F. M.; Caliceti, P.; Schiavon, O.; Sergi, M. $A d v$. Drug Deliv. Rev. 2002, 54, 587.

18. Parge, H. E.; Hallewell, R. A.; Tainer, S. A. Proc. Natl. Acad. Sci. U.S.A. 1992, 89, 6109.

19. Wang, Y.-S.; Youngster, S.; Grace, M.; Bausch, J.; Bordens, R.; Wyss, D. F. Adv. Drug Deliv. Rev. 2002, $54,547$.

20. Sato, H. Adv. Drug Deliv. Rev. 2002, 54, 487.

21. For experimental details see Supporting information.

22. Chen, J.-R.; Liao, C.-W.; Mao, S. J. T.; Chen, T.-H.; Weng, C.-N. J. Biochem. Biophys. Methods 2001, 47, 233. 